\title{
Breast feeding Optimality and Neonate's Growth after Mother Aerobic Exercise; A Randomized Controlled Clinical Trial
}

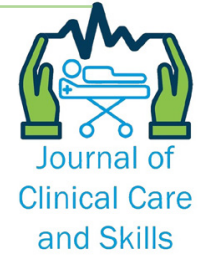

\section{ARTICLE INFO}

\section{Article Typ}

Original Research

\section{Authors}

Amini A. ${ }^{1} M S C$

Afrasiabifar A. ${ }^{2} P h D$

Taghavi S.A.V.* $P h D$

How to cite this article
Amini A, Afrasiabifar A, Taghavi S
A V. Breast feeding Optimality and
Ne-onate's Growth after Mother
Ae-robic Exercise; A Randomized
Co-ntrolled Clinical Trial. Journal
of Clinical Care and Skills.
2020;1 (1):17-21.

*Gynecology \& Obstetrics Department, Medicine Faculty, Yasuj University of Medical Sciences, Yasuj, Iran

${ }^{1}$ Nursing Department, Nursing \& Midwifery Faculty, Isfahan University of Medical Sciences, Isfahan, Iran ${ }^{2}$ Nursing Department, Nursing and Midwifery School, Yasuj University of Medical Sciences, Yasuj, Iran

\section{Correspondence}

Address: Gynecology \& Obstetrics Department, Medicine Faculty, Yasuj University of Medical Sciences, Yasuj, Iran

Phone: +98 (74) 33235041

Fax: +98 (74) 33235041

vahab.taghavi@gmail.com

\section{Article History}

Received: November 25, 2017

Accepted: January 20, 2018

ePublished: March 10, 2020

\section{A B S T R A C T}

Aims Evidence has suggested that there might be negative consequences and benefits associated with maternal exercise while breastfeeding. The aim of the present study was to determine the effect of the exercise on lactation in breastfeeding women regarding whether mothers can exercise and breastfeed without detriment to the growth of their infants.

Materials \& Methods In this randomized controlled clinical trial, 38 lactating mothers with inclusion criteria referring to breastfeeding clinic, Isfahan, Iran in 2015 to 2016 were randomly divided into the intervention and control groups. The intervention group was required to do aerobic exercises for 6 weeks ( 3 days in week for 30 minutes in day). Training of aerobic exercise under the supervision of an expert was, then, performed. An educational pamphlet of the exercises along with the CD was given to them. Control group only received the routine care. After the intervention, mother and neonate outcomes such as mother's breastfeeding interval and neonate weight were measured by the breastfeeding questionnaire. Data analysis was performed by t-test, X2 and Mann-Whitney U test.

Findings A significant difference was observed between 2 groups concerning the interval of

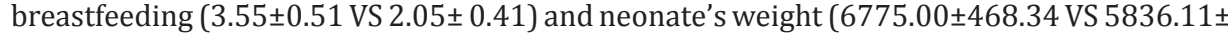
401.39; p<0.001). In the group that received aerobic exercises, the number of breastfeeding in 24 hours and neonate's weight were more than control group.

Conclusion Aerobic exercise has positive on the breastfeeding frequency and body weight of neonate. Thus, these exercises are recommended to be incorporated in postpartum care.

Keywords Aerobic exercise; Milk; Growth

\section{CITATION LINKS}

[1] A history of infant ... [2] Breastfeeding in the 21st century: Epidemiology ... [3] The effect of home visit after cesarean delivery on exclusive ... [4] Breastfeeding practices of working ... [5] Maternal and child health ... [6] Effect of postpartum exercise on mothers and their offspring ... [7] The national program for breastfeeding promotion in the Islamic Republic of Iran ... [8] Dose a regular walking have any effect on the general, trait and ... [9] The interaction between regular exercise and selected aspects ... [10] Physical exercise and the lactating woman: A qualitative ... [11] Infant acceptance of postexercise breast ... [12] Does exercise intensity or diet influence lactic acid ... [13] Breast milk composition after exercise of different ... [14] Acute effects of exercise on plasma concentrations of prolactin and testosterone in recreational women ... [15] A marathon: The immediate effect on female ... [16] Effects of dieting and physical activity on pregnancy ... [17] American Academy of ... [18] At least five a week: Evidence on the impact ... [19] A randomized study of the effects of aerobic exercise by lactating women on breast-milk volume ... [20] Breast-feeding mothers can exercise: Results of a cohort ... [21] Effect of exercise training on loss of bone mineral density during ... [22] Infant feeding guidelines for health ... [23] Major mineral concentrations in human milk do not change after maximal exercise ... [24] Infant acceptance of breast milk after maternal ... [25] The effect of selected aerobic exercise on IgA concentration in ... [26] Benefits of Yoga in Increasing Lactating Mother's Breast Milk ... [27] Randomized trial of the short-term effects of dieting compared with dieting plus aerobic exercise on lactation ... [28] The effect of endurance running activaites on prolactin, testosterone ... [29] Exercise increases prolactin-receptor expression on human ... [30] Prolactin release during exercise in normal and adrenodemedullated untrained rats submitted to central cholinergic ... [31] Relationship between stress hormones and testosterone with prolonged endurance ... 


\section{Introduction}

Breastfeeding has always been a natural part of human nutrition throughout infancy. Although an alternative over time occur, breastfeeding is an important way to foster a child newly born across cultures and countries. Over the past century, trend to be less breastfed has occurred and, today, the breastfeeding rate of $90 \%$ during the $20^{\text {th }}$ century is reported in approximately $42 \%$ of children [1, 2]. This development has been done in spite of increasing evidence of the existence of breastfeeding compared to formula and other substitutes in many ways, including security against common infancy infections.

The most common cause of premature discontinuation of breastfeeding in many studies is the lack of milk [3]. Production and secretion of milk is under the effect of prolactin and oxytocin [4]. Mother's anxiety and concern are prevented by releasing the oxytocin and prolactin. These 2 hormones cause the extraction of milk from milk ducts to the nipple cells and, thus, relax the mother; it can lead to increasing the milk spout [5].

There are a lot of the benefits of regular exercise after birth [6]. Exercise and physical activity improved mood and it is one of the factors of stress reduction [7]. After regular exercise, muscle and fat tissue sensitivity to insulin in breastfeeding mothers increase and, then, facilitate the fatty acids during lactation and improve female cardiovascular fitness [8]. However, previous studies have shown that women, who breastfeed their infants, may be reluctant to do exercise because of concerns about negative effect on the composition of breast milk, breastfeeding performance, and ultimately the growth of their baby $[9,10]$. These concerns may be originated from early experimental studies (immediately before and after exercise), showing that the concentration of lactic acid were significantly higher, and after exercise, baby milk acceptance scores were less than before the exercise [11-13]. However, the evidence showed that the effect of lactic acid in the taste of milk is great with severe sport that in this occasion, the concentration of lactic acid is much higher than usual sport done normally by many women. However, aerobic exercise can have several benefits for breastfeeding. Exercise can serve to protect lactation when energy deficiency, due to the plasma prolactin (important hormone involved in maintenance of breastfeeding), increases in response to aerobic exercise $[14,15]$.

In addition, if there is aerobic exercise on a regular basis, this reaction may increase blood glucose homeostasis and the mobilization of fat reserves during lactation period [16]. Due to the strong and compelling evidence of the benefits of regular exercise and breastfeeding, it would be reasonable that mothers who may want to do both have some hesitancies [17, 18]. In the light of the contents expressed, evidence suggested that there might be negative consequences and benefits associated with maternal exercise while breastfeeding. The aim of this study was to determine the effect of exercise on lactation in breastfeeding women, regarding whether mothers can exercise and breastfeed without detriment to the growth of their infants so as to inform clinical guidance.

\section{Materials and Methods}

This study is a randomized clinical trial carried out in AL Zahra Hospital, Isfahan, Iran during 2015 to 2016. "Table of random numbers" was used for randomization. Sample size calculation was used based on Dewey et al. [19] with $\alpha=0.05, \beta=0.80$, $\mathrm{s}_{1}=2.6, \mathrm{~s}_{2}=3.4, \mathrm{~d}=2.89$ and at least 17 people were estimated for each group to compare body weight neonate.

The participants consisted of 60 eligible women. of these, 26 did not participate due to not meeting inclusion criteria and refused to participant. Inclusion criteria included exclusive breastfeeding, 6 to 8 weeks after childbirth, lack of underlying disease, using any medicines, term pregnancy (3842 weeks), absence of any sport of activity during the past 3 months, desire to participate in study, and no smoking.

After the approval of the Ethics Committee of Yasuj University of Medical Sciences (yums.rec.1391.01), Iran, this study was conducted during February 2015 to February 2016.

After explaining the purpose of the study, written consent was obtained from all participants and everyone learned that $\mathrm{s} / \mathrm{he}$ can discontinue participating in the study based on her/his desire.

In the 4th to 6th week after birth, breastfeeding mothers were contacted with meeting invites and they were asked to write the frequency breastfeeding during past 24 hours. At the start of the study, all participants completed general and lactation status questionnaire, using the interview.

Then, breastfeeding women were randomly assigned to either the exercise group or the control group. Training aerobic exercise under the supervision of expert was performed. An educational pamphlet of the exercises along with the $\mathrm{CD}$ was given to them. Those in the exercise group undertook a program of aerobic exercise taking 45 minutes per day, 3 days per week, for 6 weeks beginning 6 to 8 weeks post-partum. The movements of aerobic exercise in each session included a three-step design, containing warm-up, workout, and cool down. Those in the control only received the routine care. If a woman missed 3 or more days of exercise in any week, an extra week would be added to the program. The researcher telephoned the participants to remind them of the timing of the interventions and follow-up. 
Breastfeeding frequency during past 24 hours was completed before and after the intervention. The women were weighed on a beam-balance scale to the nearest $10 \mathrm{~g}$. The infants' weights were measured to the nearest gram on an electronic scale. All measures were done by one researcher.

The Ethics Committee of the Yasuj Medical University of science, Yasuj, Iran reviewed the study. IRCT code is IRCT2017071435078N1.

Demographic data of the groups were expressed as mean $\pm S D$ or frequency (percentage) and comparison of these data were performed by t-test, $\mathrm{X} 2$, and Mann-Whitney U test. The normality of the distributions was tested, using the KolmogrovSmirnov test. The data were analyzed, using Statistical Package for the Social Sciences 21.0 (SPSS Inc.; Chicago, IL, USA). Significance level of $p<0.05$ was considered significant.

\section{Findings}

Mother's weight was $63.60 \pm 4.44 \mathrm{Kg}$ in intervention group and $63.27 \pm 3.26 \mathrm{Kg}$ in control group. Also neonate weight was $3316.50 \pm 190.40 \mathrm{~g}$ in intervention group and $3383.88 \pm 184.96 \mathrm{~g}$ in control group. There is no statistically significant difference for age, education, mother and neonate weight, breast feeding frequency at baseline between groups ( $p>0.05$; Table 1$)$.

Table1) Demographic and baseline characteristics of the participants ( $n=17$ in each group)

\begin{tabular}{lcc}
\hline \multicolumn{1}{c}{ Variables } & $\begin{array}{c}\text { Intervention } \\
\text { group }\end{array}$ & Control group \\
\hline Mother's age & $3(17.6 \%)$ & $3(17.6 \%)$ \\
$<25$ years & $12(70.6 \%)$ & $10(58.8 \%)$ \\
26-30 years & $2(11.8 \%)$ & $4(23.5 \%)$ \\
31-35 years & & \\
Level of education & $3(17.6 \%)$ & $3(17.6 \%)$ \\
llliterate & $1(5.9 \%)$ & $2(11.8 \%)$ \\
Elementary & $13(76.5 \%)$ & $12(70.6 \%)$ \\
High school and higher & & \\
Breastfeeding frequency & $5(29.4 \%)$ & $4(23.5 \%)$ \\
$<6$ in day & $12(70.6 \%)$ & $13(76.5 \%)$ \\
\hline 6-8 in day &
\end{tabular}

After intervention, neonate weight was $6775.00 \pm 468.34 \mathrm{~g}$ in intervention group and $5836.11 \pm 401.39 \mathrm{~g}$ in control group. There was statistically significant difference in neonate weight between 2 groups $(3.55 \pm 0.51$ VS $2.05 \pm 0.41$; $\mathrm{p}<0.001$ ).

Table 2) Comparison of breastfeeding frequency between participants after intervention ( $\mathrm{n}=17$ in each group)

\begin{tabular}{lccc}
\hline $\begin{array}{c}\text { Breast feeding } \\
\text { frequency }\end{array}$ & $\begin{array}{c}\text { Intervention } \\
\text { group }\end{array}$ & $\begin{array}{c}\text { Control } \\
\text { group }\end{array}$ & P value \\
\hline$<6$ in day & $3(17.6 \%)$ & $4(23.5 \%)$ & $<0.001$ \\
\hline $6-8$ in day & $14(82.4 \%)$ & $13(76.5 \%)$ & \\
\hline
\end{tabular}

Also, in the intervention group, breastfeeding was significantly higher than the value in the control group (Table 2).

\section{Discussion}

Regular exercise at the moderate level has a significant relationship with the weight of newborns and the frequency of breastfeeding. Mother's regular exercise during lactation not only has no adverse effects on the weight of the baby, but also increases the weight of the baby. This finding of the study agrees with $\mathrm{Su}$ et al., stating that exercise in lactating mothers does not negatively affect the weight gain and height of the baby, as well as the quantity and quality of breast milk in mothers [20]. In addition, Lovelady et al. also stated that engaging in regular exercise in lactating women does not have an adverse effect on the weight of the baby [21].

A review study has shown that breastfeeding is not affected by moderate exercise, and that moderate exercise levels do not affect the length and quality of breastfeeding. Aerobic exercise with $60 \%$ to $70 \%$ of maximum heart rate does not have an adverse effect on breastfeeding and the weight of the baby increases with the same speed [22]. Dewey et al. have studied the effects of moderate aerobic exercise 4 to 5 times per week on breast milk compositions, including fat, proteins, lactose, energy density, and breast milk volume in 38 post-partum women. The results of this study have shown that there is no significant difference between the aerobic exercise group and the control group in the weight of the baby, the volume or composition of breast milk, the weight of the baby, maternal prolactin levels, and other plasma hormones [19]. Fly et al. showed that the concentrations of major mineral elements in plasma such as calcium, phosphorus, magnesium, sodium, and potassium were unchanged after maximum exercise [23].

However, in a comparative study conducted in 1994 during 12 weeks in a group of lactating mothers, who had exercise activity 5 days a week, change in blood prolactin levels, milk composition, and weight gain of neonates were not significantly different compared with the control group. In this study, contrary to the present study, mothers' exercise did not change the weight gain of newborns. The difference in the findings of this study may be due to the early measurement of the results (immediately before and after the activity), accumulation, and concentration of lactic acid in the mother's milk after exercise. However, considering the results of studies conducted by Wallace et al. and Wright et al., the notion that the presence of lactic acid in breast milk after exercise has a negative effect on the extent of breastfeeding by the neonate is partly rejected [11, 24]. Therefore, despite the fact that lactate acid is significantly increased in breast milk after exercise, this problem does not affect the acceptance of breast milk by the neonate. However, the intensity of exercise is related to the concentration of lactic acid and the amount of lactate in extremely intense exercise is greatly increased, but this issue, as 
Breast feeding Optimality and Neonate's Growth after Mother... mentioned above, cannot have a negative effect on the acceptance of milk by the neonate.

Yet, contrary to Wallace et al. research that demonstrated that regular exercises do not have a negative effect on breast milk composition, including energy, fat, and protein (and even exercise exercises) [11], it increased the concentration of immunoglobulin and even increased the concentration of immunoglobulin and further immunity in the neonate [25].

In this study, the type of exercise exercises under the supervision of a sport specialist was considered as average level, and the amount of lactic acid in breast milk was not measured directly; but, our findings, including increase in the weight of the baby and the frequency of breastfeeding in the mothers in the exercise group indicated the acceptance of milk by neonate and increase the amount of breast milk, which was in line with the results of a study conducted by Wildan et al. [26]. The findings of the research carried out by Wildan et al. indicated the positive impact of yoga exercise on increasing lactation in breastfeeding. In this study, it has been argued that exercise results have a positive effect on secretion of oxytocin and prolactin hormone due to the mental relaxation that occurs in mothers. In addition, exercise can increase blood flow to all parts of the body, including the muscles of the chest, which itself is effective in lactation performance [26].

McCrory et al. conducted a research to determine the effect of weight loss by diet with or without aerobic exercise on lactation on 67 breastfeeding women, who fed their baby only by breastfeeding. The mothers were randomly assigned to 3 groups, including diet group $(n=22)$, diet-exercise group $(n=22)$, and control group $(n=23)$. Milk volume, milk composition, energy intake, mother weight, plasma prolactin level, and neonatal weight before and after the intervention of exercise were measured. Results showed that plasma concentration of prolactin was higher in diet and diet-exercise compared with control group. Therefore, weight loss through diet and aerobic exercise appears to be safe for lactating mothers [27]. Many studies have suggested that exercise increases prolactin levels in non-lactating women. Bagheri believes that the mean level of prolactin is significant in runners, and continuous physical training can increase the level of prolactin and reduce testosterone [28]. In his study, Dohi declared that the level of prolactin increases after running on a treadmill [29]. Lima also believes that after exercise as much as being fatigue and with moderate intensity, the levels of prolactin increase [30]. In their study, Daly et al. have found a positive relationship between exercise and the amount of prolactin. They said that the higher the exercise, the greater the prolactin levels. This prolactin level remains up to an hour after physical exercises and training [31].
There are some limitations in our study. Individual differences between participants in unpredictable psychological changes in post-partum, lack of cooperation in performing exercises, and nonaccuracy in response of questionnaire were the limitations of the present research.

\section{Conclusion}

Aerobic exercise has positive effects on the breastfeeding frequency and body weight of neonate.

Acknowledgements: The authors appreciate the research deputy of Yasuj University of Medical Sciences because of their support and also thank the participants who sincerely cooperated in this study.

Ethical Permission: After the approval of the Ethics Committee of Yasuj University of Medical Sciences (yums.rec.1391.01), Iran, this study was conducted.

Conflicts of Interests: The authors declare that there is no conflict of interests.

Authors' Contribution: Amini A. (First author), Introduction author/Methodologist/Original researcher/ Discussion author (50\%); Afrasiabifar A. (Second author), Introduction author/ Methodologist/Original researcher (20\%); Taghavi S.A. (Third author), Introduction author/ Original researcher/ Statistical analyst/ Discussion author (30\%)

Funding/Support: The present research was funded by Yasuj University of Medical Sciences, Iran.

\section{References}

1- Stevens EE, Patrick TE, Pickler R, Pickler R. A history of infant feeding. J Perinat Educ. 2009;18(2):32-9.

2- Victora CG, Bahl R, Barros AJ, Franca GV, Horton S, Krasevec J, et al. Breastfeeding in the 21st century: Epidemiology, mechanisms, and lifelong effect. Lancet. 2016;387(10017):475-90.

3- Sakkaky M, Danesh Kojuri M, Khairkhah M, Hosseini AF. The effect of home visit after cesarean delivery on exclusive breastfeeding in neonatal period. Iran J Nur. 2010;23(64):72-80. [Persian]

4- Netshandama VO. Breastfeeding practices of working women. Curationis. 2002;25(1):21-7.

5- Zolfaghari M, Nuqaby A. Maternal and child health nursing. Tehran: Boshra Publication; 2010. p. 181.

6- Larson-Meyer DE. Effect of postpartum exercise on mothers and their offspring: A review of the literature. Obes Res. 2002;10(8):841-53.

7- Ministry of Health and Medical Education. The national program for breastfeeding promotion in the Islamic Republic of Iran: Past, present and future. Tehran: Fujian Graphic; 2013. pp. 1-49. [Persian]

8- Sedaghati P, Khalaji H, Kouzehchian H, Arjmand A. Dose a regular walking have any effect on the general, trait and state anxiety of pregnant women?. Olympics. 2008;16(42):19-28.

9- Clapp JF 3rd, Little KD. The interaction between regular exercise and selected aspects of women's health. Am J Obstet Gynecol. 1995;173(1):2-9. 
10- Rich M, Currie J, McMahon C. Physical exercise and the lactating woman: A qualitative pilot study of mothers' perceptions and experiences. Breastfeed Rev. 2004;12(2):11-7.

11- Wallace JP, Inbar G, Ernsthausen K. Infant acceptance of postexercise breast milk. Pediatrics. 1992;89(6 Pt 2):1245-7.

12- Quinn TJ, Carey GB. Does exercise intensity or diet influence lactic acid accumulation in breast milk?. Med Sci Sports Exerc. 1999;31(1):105-10.

13- Carey GB, Quinn Tj, Goodwin SE. Breast milk composition after exercise of different intensities. J Hum Lact. 1997;13(2):115-20.

14- Shangold MM, Gatz ML, Thysen B. Acute effects of exercise on plasma concentrations of prolactin and testosterone in recreational women runners. Fertil Steril. 1981;35(6):699-702.

15- Hale RW, Kosasa T, Krieger J, Pepper S. A marathon: The immediate effect on female runners' luteinizing hormone, follicle-stimulating hormone, prolactin, testosterone, and cortisol levels. Am J Obstet Gynecol. 1983;146(5):550-6.

16- Dewey KG1, McCrory MA. Effects of dieting and physical activity on pregnancy and lactation. Am J Clin Nutr. 1994;59(Suppl 2):446S-52.

17- Breastfeeding and the use of human milk. American Academy of Pediatrics. Work Group on Breastfeeding. Pediatrics. 1997;100(6):1035-9.

18- Department of Health. At least five a week: Evidence on the impact of physical activity and its relationship to health. Department of Health; 2004.

19- Dewey KG1, Lovelady CA, Nommsen-Rivers LA, McCrory MA, Lönnerdal B. A randomized study of the effects of aerobic exercise by lactating women on breastmilk volume and composition. N Engl J Med. 1994;330(7):449-53.

20- Su D, Zhao Y, Binns C, Scott J, Oddy W. Breast-feeding mothers can exercise: Results of a cohort study. Public Health Nutr. 2007;10(10):1089-93. Epub 2007.
Amini A. et al.

21- Lovelady CA, Bopp MJ, Colleran HL, Mackie HK, Wideman L. Effect of exercise training on loss of bone mineral density during lactation. Med Sci Sports Exerc. 2009;41(10):1902-7.

22- National Health and Medical Research Council. Infant feeding guidelines for health workers. Australia: National Health and Medical Research Council; 1968.

23- Fly AD, Uhlin KL, Wallace JP. Major mineral concentrations in human milk do not change after maximal exercise testing. Am J Clin Nutr. 1998;68(2):345-9.

24- Wright KS, Quinn TJ, Carey GB. Infant acceptance of breast milk after maternal exercise. Pediatrics. 2002;109(4):585-9.

25- Tartibian B, Heydarlou F. The effect of selected aerobic exercise on IgA concentration in mother's milk. Harkat. 2005;(24)151-70. [Persian]

26- Wildan M, Kiswati, Jamhariyah, Primasari F.Benefits of Yoga in Increasing Lactating Mother's Breast Milk Production. J Nurs Health Sci. 2015;4(4):14-18.

27- McCrory MA, Nommsen-Rivers LA, Molé PA, Lönnerdal B, Dewey KG.. Randomized trial of the short-term effects of dieting compared with dieting plus aerobic exercise on lactation performance. Am J Clin Nutr. 1999;69(5):959-67. 28- Bagheri Hamzian Olya J, Khadem Ansari MH, Yaghmaei P. The effect of endurance running activaites on prolactin, testosterone and dhea-s levels. Urmia Med J. 2011;21(5):391-7.

29- Dohi K, Kraemer WJ, Mastro AM. Exercise increases prolactin-receptor expression on human lymphocytes. J Appl Physiol (1985). 2003;94(2):518-24. Epub 2002.

30- Lima NR, Pereira W, Reis AM, Coimbra CC, Marubayashi U. Prolactin release during exercise in normal and adrenodemedullated untrained rats submitted to central cholinergic blockade with atropine. Horm Behav. 2001;40(4):526-32.

31- Daly W, Seegers CA, Rubin DA, Dobridge JD, Hackney AC. Relationship between stress hormones and testosterone with prolonged endurance exercise. Eur J Appl Physiol. 2005;93(4):375-80. 